\title{
The effect of a textured visual field on modality dominance in a ventriloquism situation
}

\author{
MONIQUE RADEAU and PAUL BERTELSON \\ Universite libre de Bruxelles, Bruxelles 1050, Belgium
}

\begin{abstract}
Despite the often encountered affirmation that vision completely dominates other modalities in intersensory conflict, there are cases where discordant auditory information affects the localization of a visual signal. Experiment I shows that "auditory capture" occurs with a visual input reduced to a single luminous point in complete darkness, but not with a textured background. The task was to point at a flashing luminous point alternately in the presence of a synchronous sound coming from a source situated $15^{\circ}$ to one side ("conflict trials," designed to measure immediate reaction to conflict) and in its absence ("test trials," to measure aftereffects). Adaptive immediate reactions and aftereffects were observed in the dark, but not with a textured background. In Experiment II, on the other hand, "visual capture" of auditory localization was observed at the levels of both measures in the dark and with the textured background. That visual texture affects the degree of auditory capture of vision, but not the degree of visual capture of audition was confirmed at the level of aftereffects in Experiment III, where bisensory monitoring was substituted for pointing during exposure to conflict. The empirical finding eliminates apparent contradictions in the literature on ventriloquism, but cannot itself be explained in terms either of relative accuracy of visual and auditory localization or attentional adjustments.
\end{abstract}

When a spatial discrepancy exists between visual and auditory evidence which can be related to a single event, we have a strong tendency to ignore the discordance. The phenomenon has come to be called ventriloquism, since it seems to be the basis of the illusion created by the ventriloquist. Different manifestations have been described: (1) the observer reports experiencing visual and auditory signals as coming from a single source despite a sensory spatial discrepancy (Choe, Welch, Gilford, \& Juola, 1975; Jack \& Thurlow, 1973; Radeau \& Bertelson, 1974; Stratton, 1897; Thurlow \& Jack, 1973; Willey, Inglis, \& Pierce, 1937; Young, 1928); (2) pairings of an auditory signal with one of several potential visual sources are biased towards one particular source (Jackson, 1953; Thomas, 1941); (3) localizing responses, such as detecting deviations from the median plane (Witkin, Wapner, \& Leventhal, 1952) or pointing (Pick, Warren, \& Hay, 1969; Thurlow \& Jack, 1973; Weerts \& Thurlow, 1971) to signals in one modality are shifted in the direction of those in the other modality. It has recently been shown that similar shifts can still be observed after exposure to the conflicting cues, when localizing signals in one modality in the absence of any stimulation in the other modality (Canon, 1970, 1971; Radeau,

This work was carried out while the first author held a grant from the Belgian "Fonds national de la Recherche scientifique." The results were presented at the meetings of the Experimental Psychology Society in Bristol (April 1974) and at the 15th Annual Meeting of the Psychonomic Society in Boston (November 1974). The authors' address is Laboratoire de Psychologie experimentale, 117 , av. Adolphe Buyl, 1050 Bruxelles, Belgium. 1973b, 1974; Radeau \& Bertelson, 1969, 1974). The occurrence of such aftereffects shows that ventriloquism does not result simply from some substitution of cues in one modality to those in the other as a basis for responding, which was one possible explanation for the responses recorded during the conflict (Bertelson \& Radeau, 1976).

A single unitary phenomenon was, of course, not necessarily involved in all the situations which have been studied. These situations differ widely, for instance, in degree of realism. Some presented or simulated objects known to produce correlated optical and acoustic manifestations, such as the face of a person speaking (Thurlow and Jack, 1973; Witkin et al., 1952) or steam-whistle kettles (Jackson, 1953). At the other extreme, ventriloquism has been demonstrated with stimuli reduced to trains of synchronous light and sound pulses (Radeau \& Bertelson, 1974; Thomas, 1941). In the latter type of situation, the single-source interpretation could only be attained through analysis of the key stimuli themselves, whereas in the more suggestive situations, it could be established before these key stimuli were presented, on the basis of the information provided by the visible context. Simple cue substitution is, of course, less likely to occur in the first than in the second case.

The focus of the present study is the often encountered affirmation that ventriloquism consists wholly of an influence of vision on auditory localization (e.g., Choe et al., 1975; Howard \& Templeton, 1966, p. 361; Jackson, 1953; Thomas, 1941; Thurlow \& Jack, 1973; Welch, 1974, p. 370). There are, in fact, 
many examples of a tendency for vision to dominate, or "capture" other modalities when the two modalities convey discordant information about the size, the shape, or the location of a single object (Rock \& Harris, 1967; Walker, 1972). The general issue of visual dominance will not be discussed here. We shall limit ourselves to the situation of a conflict between visual and auditory information pertinent to the azimuthal position of an object. For that particular situation, we shall first show that the evidence for visual dominance is not as striking as is generally assumed, and then examine experimentally one possible determinant of the degree of dominance.

Many of the studies on which the thesis of visual dominance has been based did not actually provide the necessary evidence. Some used some kind of matching procedure, where the subjects had either to locate the auditory signals relative to several possible visual sources (Jackson, 1953; Thomas, 1941) or to give perceptual judgments of alignment or misalignment (Choe et al., 1975; Jack, 1973; Thurlow, 1973). What they demonstrated was thus an altered correspondence between points in auditory and in visual space, which cannot, without further proof, be attributed solely to the prevalence of visual cues. In some other studies, auditory localization was measured separately, and an influence of discordant visual information was actually demonstrated (Kalil \& Freedman, 1967; Weerts \& Thurlow, 1971; Witkin, et al., 1952). But visual localization was not measured, hence one cannot affirm that the change was confined to audition.

In those studies where both visual and auditory localization have been measured, conflicting results have been obtained. Pick, Warren, and Hay (1969) had their subjects localize a visual target, a loudspeaker, in the presence of discordant sounds, and inversely asked them to localize the sounds in the presence of discordant information from the visible loudspeaker. Vision was found to influence auditory localization to a considerable extent, while the opposite influence was small and nonsignificant. In that study, visual dominance was thus complete. The present authors have found, in several experiments, that exposure to trains of synchronous flashes and sound bursts, with a spatial discrepancy created by viewing the flashes through prisms, produced aftereffects in both visual and auditory localization (Radeau, 1973b, 1974; Radeau \& Bertelson, $1969,1974)$. In general, visual aftereffects were smaller than auditory ones. Cannon (1970), using a similar design, found aftereffects in both visual and auditory localization in a condition where the subjects had to indicate the origin of auditory stimulation during the exposure period, and in auditory localization only, in a condition where they had to indicate the origin of the visual stimulation. Radeau (1974) also found that pointing instructions during exposure affected the relative size of the aftereffects observed in the two modalities, but found significant visual adaptation even after visual pointing.

It appears thus that, contrary to the extreme version of the visual dominance thesis, visual location can be affected by conflicting auditory information. The effect, however, is less systematically found than the opposite one, and, when it occurs, it tends to be of lesser amplitude. Its occurrence depends on factors which are not yet well established.

Examination of the displays used in the various experiments suggested that the degree of articulation of the visual field might be relevant. In our experiments, where visual adaptation was always found, the visual input was reduced to a simple luminous point in a totally dark field. On the other hand, the subjects of Pick et al. (1969), who showed complete visual dominance, saw the whole setup illuminated, with the target loudspeaker in position. Similarly, Canon (1970), who found visual adaptation after auditory pointing only, not after visual pointing, gave his subjects a full view of the apparatus. In both these studies, however, the relevant factor may have been the specific knowledge about the origin of the sound derived from the sight of the actual source, a loudspeaker for Pick et al. and a moving clapper for Canon. The contextual information provided in the visual modality might have contributed to shift modality dominance in the direction of vision. On the other hand, the autokinetic phenomenon, and other data also, show that a visual framework is necessary to stabilize visual localization, and that, in particular, involuntary shifts of the eye occur in the dark (Matin, 1972). Visual articulation per se might thus be the critical factor.

The present study was undertaken to examine the notion that dominance of vision on audition is stronger when the visual stimulation appears in a textured field than in complete darkness. The kinds of simplified displays used in our previous experiments were employed again: trains of tones and trains of punctual flashes. Conflict was created by presenting trains in the two modalities in exact synchrony, but with the respective sources separated by a $15^{\circ}$ angle. In the previous studies, the conflict was obtained by having the visual input displaced by a prismatic device. Advantage was taken of the present study to check that the obtained adaptation was due to the spatial discordance and not to some other effect of the optical device. To separate the effect of articulation of the visual field from that of contextual suggestion of common origin, special care was taken not to provide any information 
regarding the origin of light and sounds in the condition with textured background. Since most previous experiments have considered either exclusively the reaction to the conflict situation (Pick, et al., 1969) or exclusively the aftereffects (Canon, 1970, 1971; Radeau \& Bertelson, 1974), it was decided in the present study to examine the effect of textured background at both levels simultaneously. Experiment I examined the effects of discordant auditory stimulation on pointing at a visual target, and Experiment II, the effects of discordant visual input on pointing at an auditory target. In both experiments, subjects were instructed to point at one target during exposure to conflict. To check if the size of aftereffects was affected by this condition, in Experiment III a bisensory monitoring task, similar to the one introduced by Radeau and Bertelson (1974), was used during exposure to conflict.

\section{APPARATUS}

The apparatus is shown in Figure 1. It is a slightly modified version of the one used in our previous experiments (Radeau, 1973b, 1974; Radeau \& Bertelson, 1974). Basically, it consists of a semi-cylindrical enclosure divided into two compartments by a horizontal panel. The upper compartment is limited by an opaque screen. A target holder, attached to a vertical rod which can be rotated around the outer side of the cylinder by a pivot system, protrudes under the lower edge of the screen through a light trap. The lower compartment is limited by a transparent screen, whose inner circumference falls exactly below the course of the target. During pointing tests, the subject placed the tip of the finger against the transparent screen. The experimenter, who sat on the other side of the apparatus, could read the position of the finger to the nearest degree on a graduation painted on the screen. A pointer fastened to the target holder came in contact with the same graduation which could thus also be used to position the target. The subject sat on an adjustable stool with his chin on a chinrest, placed at the edge of the horizontal panel, in the axis of the cylinder.

The target holder consisted of a curved rod which held a small loudspeaker in the middle and one neon pea-lamp $10.5 \mathrm{~cm}$ on either side of the loudspeaker. From the subject's position, the separation between either lamp and the loudspeaker subtended an angle of $15^{\circ}$. The loudspeaker was a Philips EL 3775/00 earphone (diameter $3 \mathrm{~mm}$ ). Sound bursts were produced by feeding it with 50 -msec pulses of $50 \mathrm{~Hz}$ ac. The lamps were red LED lamps (Monsanto Type MV50). The stimuli were controlled by an automatic programming system.

For the present experiment, the interior face of the opaque screen was covered with a $13-\mathrm{cm}$-high sheet of white paper with vertical black stripes, $0.5 \mathrm{~cm}$ wide, at $4.5-\mathrm{cm}$ intervals. The lamps, situated on either side of the enclosure, could provide a dim illumination ( $\pm 0.02 \mathrm{fL}$ ) which made the background visible for the subject. Since it was not desirable that the target itself became visible, a 2-cm-high stripe of thin wiremesh was fixated on the horizontal panel immediately in front (for the subject) of the course of the target. With this setup, the light of the target became visible through the mesh,but the subject did not see the target holder itself and, in particular, obtained no information concerning the relation of the lamp and the loudspeaker.

During a session, the subject received no visual stimulation other than that provided by the target and, on some sessions, by the illuminated background. He wore a black cape, attached around the neck, which prevented any of the light used by the experimenter on the other side of the apparatus from reaching him through the lower compartment.

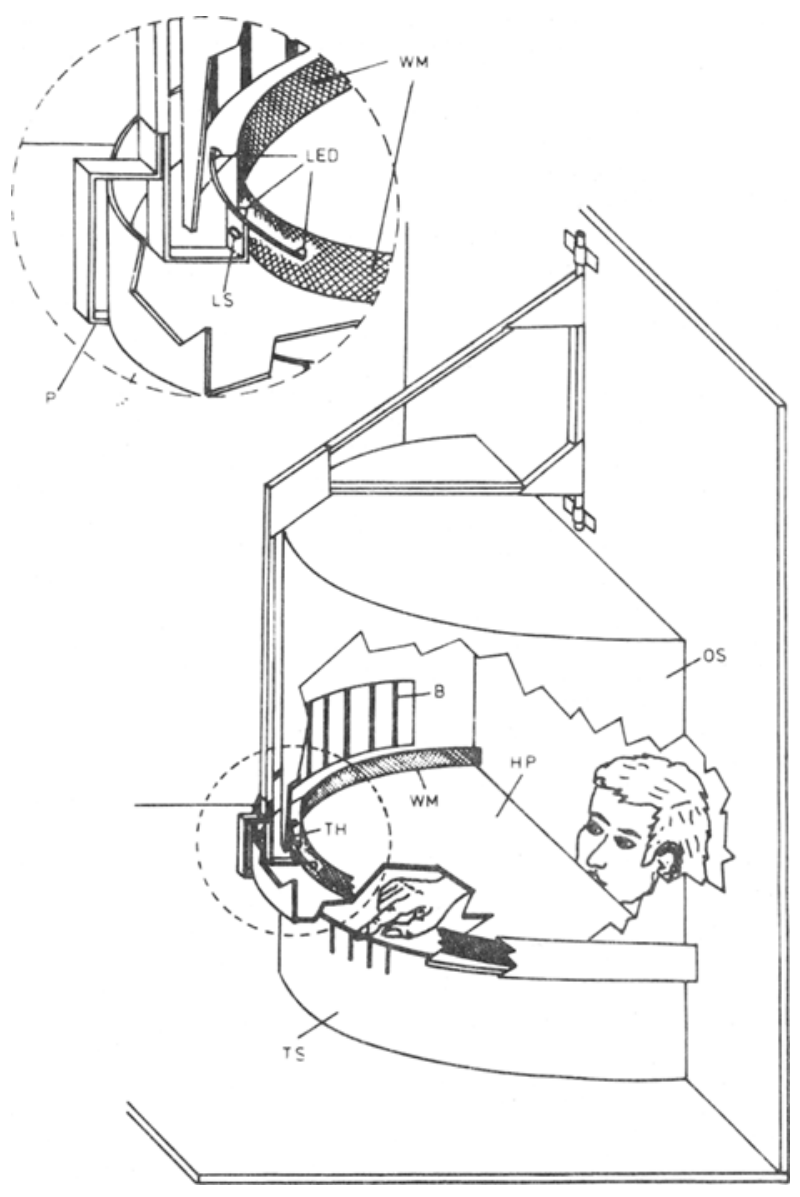

Figure 1. Schematic view of the setup. HP, horizontal panel; OS, opaque screen; TS, transparent screen; TH, target holder; P, pointer; LS, loudspeaker; LED, lamps; WM, wiremesh screen; B, textured background.

\section{EXPERIMENT I}

The purpose of this experiment was to test the hypothesis that visual localization is less affected by spatially discordant auditory input when the visual target is seen against a textured background than without such a background. The hypothesis was examined at the level of both the immediate reaction to the conflict situation, i.e., when the subject pointed at the visual target with competing auditory stimuli, and of the aftereffect, i.e., when subsequently pointing at the visual target presented alone. To obtain a detailed picture of the time course of the effect, a test for aftereffects was conducted after every adaptation trial.

\section{Method}

The testing consisted of test trials, conflict trials, and catch trials. On a test trial, one of the two light bulbs produced a train of six 50 -msec flashes separated by 450 -msec intervals. The subject's task was to indicate the position of the light with the right index finger. On a conflict trial, the loudspeaker produced six $50-\mathrm{msec}$ sound pulses in exact synchrony with the six flashes in the light 
bulb. The subject's task was also to point at the position of the light. A catch trial was identical to a conflict trial, except that the last or the last two sound pulses were omitted. The subject was instructed to signal such occasions by saying "son" (sound). These trials were meant to prevent the subjects from ignoring the sounds altogether.

Each session started with two blocks of 15 test trials. These served to measure eye-hand coordination before exposure to conflict. They will be called "pretests." They were followed by four experimental blocks. Each of these consisted of 15 conflict trials, each followed immediately by a test trial, and one to four catch trials interspersed at random between a test trial and the following conflict trial. Trials succeeded each other at 10-sec intervals, and there was a 1-min pause between two blocks.

On conflict and catch trials, the light target was positioned in one of five positions centered around the median plane, namely in the median plane and $2^{\circ}$ and $4^{\circ}$ on either side. Each position was used three times during the 15 conflict trials of a block. For test trials, the light was positioned either in one of the same five positions or in one of two other groups of five positions, each subtending an $8^{\circ}$ angle and centered, respectively, $15^{\circ}$ to the left and $15^{\circ}$ to the right. Each of the 15 positions was used once in each block. The visual stimulation was thus always distributed symmetrically around the median plane. The same light bulb was used throughout each session, which means that during a session, the sound either always came from $15^{\circ}$ to the right or always came from $15^{\circ}$ to the left of the light.

Eight paid volunteers participated in four sessions each. Two sessions were run with the textured background visible (condition $T$, for textured), two in complete darkness (condition D). Four subjects did the two sessions in condition $T$ first, the four others, in condition $D$. Of the two sessions run in the same condition, one was run with the sound $15^{\circ}$ to the left of the light, the other, $15^{\circ}$ to the right. In each subgroup of four subjects, two had the sound to the left first.

The subjects, who were all right-handed, did all the pointing with the right index finger. They rested the left forearm on the table top, the hand gripping the holder of the chinrest. Between pointings, they were instructed to bring the right hand back to a resting position on top of the left hand.

The subjects were given no information whatsoever concerning the spatial relation between the sources of stimulation. They were at no time allowed to see the target holder. At the end of the last experimental session, they were asked the question "When the sound occurred, did it come from the same location as the light?"

\section{Results}

An error was scored as positive when it went in the direction of the sound. For each subject and each session, mean error on pretests was subtracted from mean error on conflict trials, to give a measure of the immediate effect of discordant auditory stimulation, and also from mean errors on test trials, to give a measure of aftereffect. The mean values of the two resultant measures appear in Table 1. The results from the two sessions run under the same condition but with opposite directions of discordance have been pooled. Also given in Table 1 are the results of the $t$ tests applied to the hypothesis that the shifts do not differ from zero.

In condition $\mathrm{D}$, the shifts observed at the level of both the immediate reactions and the aftereffects are significant at $p=.05$. Unilateral tests were applied, since shifts in the direction of the sound had been predicted. In condition $T$, very small
Table 1

Experiment I: Immediate Effects of Discordant Auditory Information on Visual Pointing (Mean Error on Conflict TrialsMean Error on Pretests) and Aftereffects (Mean Error on Test Trials-Mean Error on Pretests) and Means Over Both Directions of Discordance

\begin{tabular}{|c|c|c|}
\hline \multirow[b]{2}{*}{ Score } & \multicolumn{2}{|c|}{ Condition } \\
\hline & Textured (T) & Darkness (D) \\
\hline & \multicolumn{2}{|c|}{ Immediate Effect } \\
\hline mean & $+.32^{\circ}$ & $+1.52^{\circ}$ \\
\hline $\mathfrak{t}(7)$ & .80 & 2.26 \\
\hline \multirow[t]{2}{*}{$\mathrm{p}$, one-tailed } & n.s. & .05 \\
\hline & \multicolumn{2}{|c|}{ Aftereffect } \\
\hline mean & $+.24^{\circ}$ & $+1.32^{\circ}$ \\
\hline$t(7)$ & .61 & 2.27 \\
\hline $\mathrm{p}$, one-tailed & n.s. & .05 \\
\hline
\end{tabular}

Note-An effect is scored as positive when it goes in the direction of the conflicting auditory input.

shifts are observed, which are both nonsignificant.

The differences between the shifts obtained in the two conditions were tested with t tests for correlated observations. For both the immediate reaction $[\mathrm{t}(7)=1.36]$ and the aftereffect $[\mathrm{t}(7)=1.39]$, the difference is nonsignificant. However, if only the two first experimental blocks of the session are considered, the .025 level is reached both for immediate reactions $[\mathrm{t}(7)=2.18]$ and aftereffects $[\mathrm{t}(7)=2.36]$.

In Figure 2, mean errors, pooled again across the two directions of discordance, have been represented

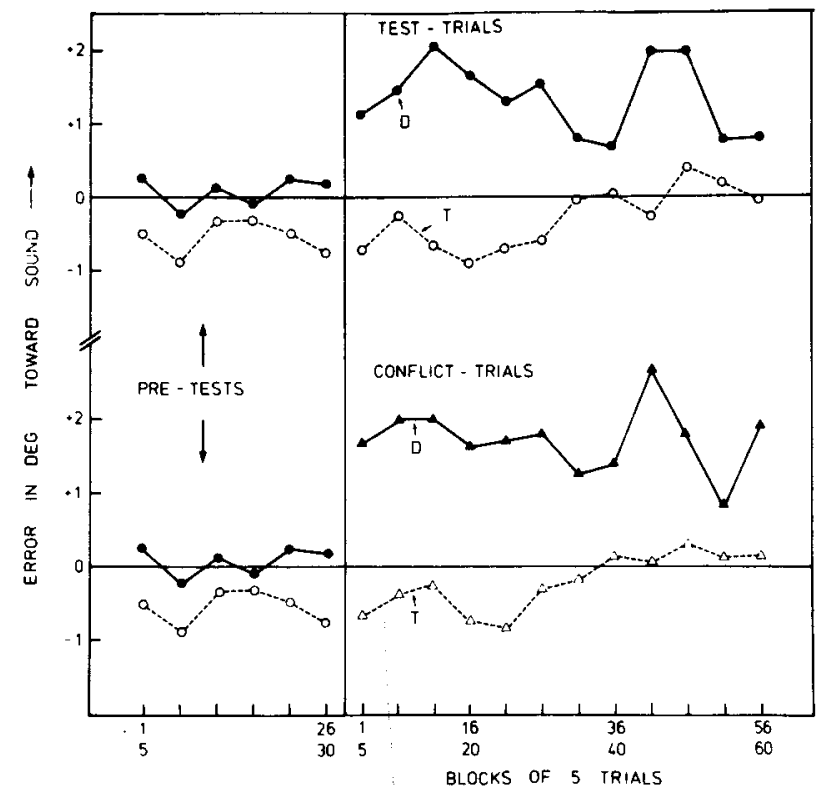

Figure 2. Experiment I (visual pointing). Mean pointing errors for successive blocks of five trials, averaged over subjects (eight) and directions of discordance (two): above, pretests and test trials; below, pretests (circles) and conflict-trials (triangles); open symbols and dotted lines, with textured background; filled symbols and heavy lines, darkness. Errors are scored as positive when they go in the direction of the discordant sound. 
as functions of time, separately for conflict and for test trials. Averages over successive groups of five trials are represented. It appears that in condition $\mathrm{D}$, pointings on conflict trials show an immediate attraction by the noise: the effect reaches the asymptotic level of about $1^{\circ}$ on the very first block. On test trials also, adaptation reaches the asymptotic level on the first block. In condition $T$, no shift is apparent during the first half of the session, but a slight tendency to a displacement in the direction of the sound develops during the second half for both types of trials. These small shifts are responsible for the fact that the differences between the conditions are significant during the first half of the session only.

Figure 2 shows a remarkable degree of parallelism between the evolution of responses on conflict trials and on test trials. To examine this aspect further, product-moment correlations were calculated between the mean values (i.e., averaged across subjects) of the two scores on successive trials, separately for each session. The obtained values, which appear in Table 2, are all highly significant. These correlations of course can have been influenced by both changes in apparent visual location and changes in felt finger position. In these experiments, where pointing is done with the right hand throughout, there is a general tendency for pointing to shift progressively to the left, which combines additively with the effect of visual adaptation on sessions with the sound to the left and negatively on these with the sound to the right. This is probably the reason why correlations are higher on sessions with sound to the left.

The data from test trials were examined for a possible influence of the position of the target. No systematic effect is apparent (Table 3 ). Since conflict trials were all run with the targets in the central zone, if adaptation was specific to the particular region in which the discordance had been experienced, the aftereffects should be smaller for the lateral zones. They are, if anything, larger.

When questioned regarding the origin of the sound, only one subject out of the eight said it came from a location other than the light. Sound omissions on catch trials were practically always detected.

Table 2

Experiments I and II: Product-Moment Correlations Between Mean Errors (Averaged Over the Eight Subjects) on Successive Conflict and Test Trials (60 Pairs)

\begin{tabular}{cccc}
\hline & & \multicolumn{2}{c}{ Condition } \\
Experiment & Direction of Discordance & T & D \\
\hline \multirow{2}{*}{ I } & Sound left & $.69^{*}$ & $.77^{*}$ \\
& Sound right & $.59^{*}$ & $.41^{*}$ \\
II & Light left & $.66^{*}$ & $.54^{*}$ \\
& Light right & $.53^{*}$ & $.39^{* *}$ \\
& $*{ }^{*} p=.001$ & $* * p=.01$
\end{tabular}

Table 3

Experiment I: Visual Aftereffects as Functions of Target Position

\begin{tabular}{|c|c|c|c|}
\hline & Left & $\begin{array}{l}\text { Target Position } \\
\text { Center }\end{array}$ & Right \\
\hline Condition & 19 to $11^{\circ} \mathrm{L}$ & $4^{\circ} \mathrm{L}$ to $4^{\circ} \mathrm{R}$ & 11 to $19^{\circ} \mathrm{R}$ \\
\hline $\begin{array}{l}\mathrm{T} \\
\mathrm{D}\end{array}$ & $\begin{array}{l}+.27^{\circ} \\
+1.63^{\circ}\end{array}$ & $\begin{array}{l}+.18^{\circ} \\
+.96^{\circ}\end{array}$ & $\begin{array}{l}+.28^{\circ} \\
+1.37^{\circ}\end{array}$ \\
\hline
\end{tabular}

\section{DISCUSSION}

The hypothesis is supported by the results: at the levels both of the immediate reaction and of aftereffects, visual localization is affected by the discordant auditory input when the visual target is seen on a completely dark background, but not on a textured one.

Apart from that confirmation of the main hypothesis, the results have brought useful information on several points.

(1) Adaptation as a result of exposure to a discordance resulting from separation of the actual sources has been demonstrated. The previous results obtained with a prismatically induced discordance were thus probably really due to apparent spatial separation, and not to some other effect of the optical device that was used.

(2) Reaction to the discordant auditory information recorded on conflict trials and aftereffects measured on subsequent test trials are of nearly equal amplitudes, and are subject to correlated changes. Both sets of data presumably thus reflect the same underlying phenomena, namely (a) progressive shifts in visual location resulting from exposure to the discordance, and (b) progressive shifts in felt hand position. The size of the first component is apparently little affected by the fact that it is measured in the presence of the discordant sound or in its absence.

\section{EXPERIMENT II}

Experiment I showed that a textured visual field reduces susceptibility of visual location to the influence of discordant auditory inputs. In the present experiment, a complementary hypothesis was examined: that a textured visual field increases the effect of discordant visual input on auditory location. The experiment was the exact parallel of the previous one, except for the fact that auditory pointing was performed throughout.

\section{Method}

The same three kinds of trials-test trials, conflict trials, and catch trials-were run. On test trials, a train of six sound pulses was produced and the subject indicated the apparent position of their source by pointing with the right index finger. Conflict trials were identical to those of Experiment I, but the subject was instructed to point at the auditory target. On catch trials, the last or the last two flashes were omitted. To be able 
to report these occasions, the subject had thus to monitor the visual input while pointing at the auditory one. The auditory target occupied the same positions, distributed symmetrically relative to the median plane, as the visual target in Experiment $I$.

Eight new subjects participated in four sessions each. Two sessions were run under condition $T$ and two under condition $D$. For each condition, one session was run with the light $15^{\circ}$ to the left of the loudspeaker, and the other with the light to the right. The order of sessions was balanced in the same way as in Experiment I.

At the end of the fourth session, each subject was asked if, on those trials where lights were seen, the lights came from the same location as the sound.

\section{Results}

Immediate effects of visual discordant information and aftereffects were compared following the same principles as in Experiment I. The mean values over sessions and subjects appear in Table 4, together with the results of one-tailed t-tests.

Both immediate effects and aftereffects are significant in both conditions. On the other hand, there are no significant differences between the conditions (for immediate effects, $t=0.7$; for aftereffects, the difference is null).

The evolution of the errors with time appears in Figure 3. For both types of trials, the influence of visual discordance is virtually immediate. Correlations between mean errors on corresponding conflict and test trials were calculated for each session. As appears in Table 2, all the obtained values are highly significant. Here, again, the sessions with discordant input to the left give higher correlations.

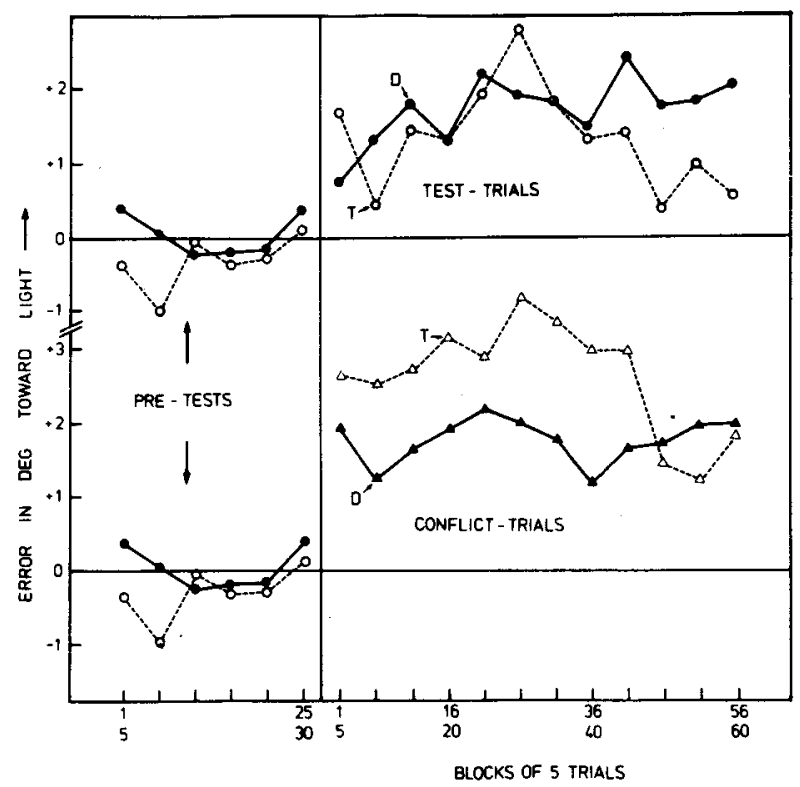

Figure 3. Experiment II (auditory pointing). Mean pointing errors for successive blocks of five trials: above, pretests and test trials; below, pretests (circles) and conflict-trials (triangles); open symbols and dotted lines, with textured background; filled symbols and heavy lines, darkness. Errors are scored as positive when they go in the direction of the discordant light.
Table 4

Experiment II: Immediate Effects of Discordant Visual Information on Auditory Pointing and Aftereffects

\begin{tabular}{|c|c|c|}
\hline & \multicolumn{2}{|c|}{ Condition } \\
\hline & Textured (T) & Darkness (D) \\
\hline & \multicolumn{2}{|c|}{ Immediate Effect } \\
\hline mean & $+2.91^{\circ}$ & $+1.68^{\circ}$ \\
\hline$t(7)$ & 3.14 & 2.15 \\
\hline \multirow[t]{2}{*}{$\mathrm{p}$, one-tailed } & .01 & .05 \\
\hline & \multicolumn{2}{|c|}{ Aftereffect } \\
\hline mean & $+1.66^{\circ}$ & $+1.66^{\circ}$ \\
\hline$t(7)$ & 3.00 & 2.36 \\
\hline p, one-tailed & .01 & .05 \\
\hline
\end{tabular}

Table 5

Experiment II: Auditory Aftereffects as Functions of Target Position

\begin{tabular}{|c|c|c|c|}
\hline & Left & $\begin{array}{l}\text { Target Position } \\
\text { Center }\end{array}$ & Right \\
\hline Condition & 19 to $11^{\circ} \mathrm{L}$ & $4^{\circ} \mathrm{L}$ to $4^{\circ} \mathrm{R}$ & 11 to $19^{\circ} \mathrm{R}$ \\
\hline $\begin{array}{l}\mathrm{T} \\
\mathrm{D}\end{array}$ & $\begin{array}{l}+1.43^{\circ} \\
+1.88^{\circ}\end{array}$ & $\begin{array}{l}+2.25^{\circ} \\
+1.57^{\circ}\end{array}$ & $\begin{array}{l}+1.31^{\circ} \\
+1.53^{\circ}\end{array}$ \\
\hline
\end{tabular}

Mean errors on test trials were calculated separately for each of the three zones in which those trials were conducted. Table 5 reveals no effect whatsoever.

To the question regarding the position of the visual source, seven out of the eight subjects answered that it was different from the auditory source, and the eighth that it was the same. Detection performance on catch trials was faultless.

\section{Discussion}

The results are not symmetrical to those of Experiment I. While a luminous point in complete darkness is more susceptible to attraction by discordant auditory input than one seen on a textured background, both are capable of influencing auditory localization.

There is an apparent correlation between this asymmetry and the pattern of discrepancy detections. The discordance was much more frequently reported in Experiment II than in Experiment I. A similar pattern was observed before by Radeau (1973a, Experiment 2), and she suggested that auditory monitoring, unlike visual monitoring, could be performed without registering the azimuth of the source. Whatever the reason, cognitive adjustments consequent on conscious registration of the discordance were more likely to occur in the conditions of Experiment II than in those of Experiment I. For these reasons, it was felt desirable to check if the asymmetry would still be observed under conditions where it could not be attributed to this factor. The question is examined in Experiment III.

A strong parallelism between immediate reactions and aftereffects has been obtained, as in Experiment I. In that respect, the present experiment has 
not confirmed a puzzling pattern of data obtained by Radeau (1974) in her condition where subjects pointed at the auditory target during exposure to conflict: during that period, a repulsion effect occurred, i.e., pointing was displaced away from the discordant visual input. The main difference between the two experiments is that conflict trials were run by long blocks in the previous one and alternated with test trials in the present one, but it seems doubtful that this feature could explain the discrepancy.

\section{EXPERIMENT III}

In the two first experiments, pointing was used both on conflict trials and test trials. This procedure was used to examine whether or not the influence of texture was found at the levels of both immediate effects of discordant heteromodal stimulation and aftereffects. But instructions to point at the apparent location in one modality of a bisensory target unavoidably suggests to the subjects the existence of separate sources. As has been remarked in the preceding discussion section, with auditory pointing instructions, most subjects detected the discrepancy, while visual pointing had no such effect. The present experiment was run to control for a possible influence of the pointing instructions on the obtained adaptive shifts. No pointing whatever was requested on conflict trials: the subjects only had to monitor both flashes and sound pulses for occasional omissions. This task has been called "bisensory monitoring." Since no localization responses were collected on conflict trials, adaptive shifts could be measured only as aftereffects. Except for this change in the task on conflict trials, the general design was the same as in the two previous experiments.

\section{Method}

Test trials, conflict trials, and catch trials were run again. On test trials, either light or sound pulses were presented, in random order, with equal frequencies. They occurred in the same three zones centered, respectively, in the median plane and $15^{\circ}$ to the left and to the right. On conflict trials, it was impossible to insure presentation symmetry in both modalities. The solution was adopted of reserving the central locations (in the median plane and $2^{\circ}$ and $4^{\circ}$ on either side) to the signal which was going to be presented on the following test trial. In that way, performance on test trials cannot be influenced by an eventual effect of presentation asymmetry on immediately preceding conflict trials, but could, of course, be affected by the asymmetry which exists on conflict-trials of the other category. Recall that Radeau and Bertelson (1974) found no effect of presentation asymmetry on auditory pointing. No pointing was requested on conflict or on catch trials. On catch trials, the last or the last two light or sound pulses were omitted, and the subjects were instructed to signal these occasions by saying "sound" or "light."

Eight new subjects participated in four sessions each, two under condition $T$ and two under condition $D$. For each condition, the light was presented to the right of the sound during one session and to the left during the other. The order of sessions was counterbalanced across subjects. Each session consisted of one block of $\mathbf{3 0}$ test trials, called pretests, and two experimental blocks of 30 conflict trials, each followed by one test trial, with one to four catch trials in each modality. Catch trials were always presented between a test and a conflict trial.

At the end of the fourth session, seven of the eight subjects were asked if sound and light seemed always to occur in the same location on conflict trials. The question was inadvertently omitted for one subject.

\section{Results}

Mean aftereffects, calculated as in the previous experiments, are given for each condition and each modality in Table 6, together with the results of the $t$ tests. For visual pointing, there is a significant aftereffect in condition $D$, not in condition $T$. The difference between the two conditions was tested with a t test for correlated observations, which gave $t(7)=1.83, p$ (one-tailed) $=.056$. For auditory pointing, a significant aftereffect is obtained in both conditions, and the difference between the conditions is nonsignificant. In condition $D$, the auditory aftereffect is larger than the visual one $[t(7)=3.03$, $\mathrm{p}=.011$.

To the question regarding the origin of the signals, four subjects answered that they came from the same location and three that there had sometimes been two sources, sometimes only one.

\section{Discussion}

Experiment III confirms completely the pattern formed by the aftereffects in Experiments I and II: the textured background makes visual location resistant to recalibration through exposure to discordant auditory input; it has no detectable influence on the susceptibility of auditory location to recalibration through exposure to discordant visual inputs. There is thus a genuine asymmetry in the effects of visual texture on auditory and visual capture.

Comparison of the results of the present experiment with those of the two previous ones shows that the auditory aftereffects are much larger in Experiment III than in Experiment II, while the visual aftereffects are only slightly larger in Experiment III than in Experiment I. These results confirm a pattern which had already emerged from the comparison of our previous experiments where the

Table 6

Experiment III : Aftereffects of Bisensory Monitoring 28 Functions of Articulation of the Visual Field

\begin{tabular}{|c|c|c|}
\hline \multirow[b]{2}{*}{ Score } & \multicolumn{2}{|c|}{ Condition } \\
\hline & Textured $(\mathrm{T})$ & Darkness (D) \\
\hline & \multicolumn{2}{|c|}{ Visual Pointing } \\
\hline $\begin{array}{l}\text { mean } \\
t(7)\end{array}$ & $\begin{array}{r}+.62^{\circ} \\
1.12^{\circ}\end{array}$ & $\begin{array}{r}+1.57^{\circ} \\
4.61\end{array}$ \\
\hline \multirow[t]{2}{*}{$p$, one-tailed } & n.s. & .005 \\
\hline & \multicolumn{2}{|c|}{ Auditory Pointing } \\
\hline mean & $\begin{array}{c}+3.32^{\circ} \\
7.83\end{array}$ & $\begin{array}{c}+3.15^{\circ} \\
4.29\end{array}$ \\
\hline
\end{tabular}


performance of auditory pointing during exposure to conflict (Radeau, 1974) seemed similarly to produce a reduction of auditory aftereffects in comparison to those obtained after bisensory monitoring (Radeau \& Bertelson, 1974).

\section{GENERAL DISCUSSION}

The influence of the articulation of the visual field on modality dominance has been clearly established. When a luminous point is presented in an otherwise dark field in synchrony with a spatially discordant sound pulse, mutual attraction occurs, so that the reported position of each signal is displaced toward the other. These changes involve a recalibration of apparent positions which for each modality manifests itself in the form of an aftereffect. When, on the other hand, the luminous point is seen against a textured background, visual location becomes much more resistant to interference from auditory cues, while the effect of visual cues on auditory location remains the same.

The effects can probably be attributed to the factor of visual texture itself, for in the present experiments the textured background provided no contextual information about the origin of the key signal.

The contradictions in the literature regarding modality dominance which were described in the introduction can be accounted for in terms of this factor. The experiments where no auditory capture occurred were all run with a textured visual field, and some degree of auditory capture has been uniformly observed for a single luminous point in a dark field.

Why is a textured visual field more resistant to auditory capture than a single isolated point? There is, for the time being, no really convincing answer.

One possibility which seemed worth exploring was a relation to relative accuracy of localization in the two modalities. It has often been suggested (e.g., Choe, et al., 1975; Howard \& Templeton, 1966, p. 361; Kaufman, 1974, p. 437) that cross-modal interaction consists of the substitution of cues in one modality to those in the other as a basis for localization responses, and that in this process the more reliable cues would tend to be elected. The hypothesis has generally been associated with the visual capture hypothesis, hence substitution of visual cues to proprioceptive or auditory ones has only been considered, but one would apply it to cases of mutual attraction by assuming a variable substitution process, where cue selection changes from trial to trial with a bias favoring the more accurate modality. This kind of mechanism would explain our results if the introduction of visual texture increased the superiority in accuracy of visual over auditory localization. Data leading to the expectation of higher visual accuracy in a textured field were mentioned in the introduction. On the other hand, Warren (1970) and Platt and Warren (1972) have recently shown that auditory localization can be improved by the provision of a visual framework.

The effect of visual texture on consistency of localization in the present experimental situation could be assessed by computing mean intrasubject standard deviations of pointing errors. These data appear in Table 7. The measure of consistency less influenced by cross-modal interaction is provided by the pretests. For visual pointing, it appears that there is no effect of visual texture on the variance of the errors, either in Experiment $I$ or in Experiment III. For auditory pointing, the results go in the direction of Warren's findings: the standard deviation is smaller in condition $T$ than in condition $D$ for all eight subjects in Experiment II $(\mathrm{p}=.008$ by a twotailed sign test) and for seven subjects out of eight in Experiment III $(\mathrm{p}=.07)$. In conclusion, the condition (D) where audition has the strongest effect on visual localization is the one where auditory localization has the larger variance, a result exactly opposite to the prediction from the cue substitution hypothesis.

Before leaving the cue substitution hypothesis, let us note that it is also contradicted by another aspect of the data shown in Table 7. On the conflict trials of Experiment II, if subjects responded most of the time on the basis of the visual cues, their standard deviations should approach the level observed for visual pointing in Experiment $I$. It clearly does not.

Another possible explanation for the effect of visual texture was suggested by data showing that modality dominance can be influenced by the way attention is distributed between the modalities in a conflict situation. The notion was first introduced by Canon (1970) following his finding of an effect of pointing instructions on the relative sizes of auditory and visual aftereffects. It has recently received impressive support in a study dealing with a conflict

Table 7

Experiments I, II, and III : Intrasubject Standard Deviations of Pointing Errors (Means Over Directions of Discordance and Subjects)

\begin{tabular}{ccccccc}
\hline \multirow{2}{*}{$\begin{array}{c}\text { Modal- } \\
\text { Experiment }\end{array}$} & & \multicolumn{3}{c}{ Type of Trial } \\
& ity & Condition & Pretests & Conflict & Tests \\
\hline \multirow{2}{*}{ I } & V & T & 2.10 & 2.03 & 2.37 \\
& & D & 2.12 & 2.26 & 2.48 \\
II & A & T & 2.85 & 3.43 & 3.48 \\
& & D & 4.49 & 3.63 & 4.13 \\
III & V & T & 1.47 & & 1.76 \\
& & D & 1.55 &. & 1.90 \\
& A & T & 2.20 & & 2.82 \\
& & D & 2.67 & & 3.05 \\
\hline
\end{tabular}


between vision and the haptic sense reported by Kelso, Cook, Olson, and Epstein (1975). For our situation, one could imagine that with the textured background more attention is devoted to the visual input than is the case in the dark. The effect of texture on auditory capture could be explained in that way. But the same principle would predict more visual capture of audition with the textured background, and this is not observed.

The fact that visual capture and auditory capture are not affected symmetrically by visual texture makes it impossible to account for the present results in terms of a single general principle like attention distribution or relative accuracy. Distinct specific mechanisms seem to be responsible for the two effects.

\section{REFERENCES}

Bertelson, P., \& Radeau, M. Ventriloquism, sensory interaction, and response bias: Remarks on the paper by Choe, Welch, Gilford, and Juola. Perception \& Psychophysics, 1976. 19, 531-535.

CANON, L. K. Intermodality inconsistency of input and directed attention as determinants of the nature of adaptation. Journal of Experimental Psychology, 1970, 84, 141-147.

Canon, L. K. Directed attention and maladaptive "adaptation" to displacement of the visual field. Journal of Experimental Psychology, 1971, 88, 403-408.

Choe, C. S., Welch, R. B., Gilford, R. M., \& Juola, J. F. The "ventriloquist effect:" Visual dominance or response bias? Perception \& Psychophysics, 1975, 18, 55-60.

Howard, I. P., \& Templeton, W. B. Human spatial orientation. London: Wiley, 1966.

JACK, C. E., \& ThURLOW, W. R. Effects of degree of visual association and angle of displacement on the "ventriloquism" effect. Perceptual and Motor Skills, 1973, 37, 967-979.

JACKs ON, C. V. Visual factors in auditory localization. The Quarterly Journal of Experimental Psychology, 1953, 5, 52-65.

KA UFMAN, L. Sight and mind, an introduction to visual perception. New York: Oxford University Press, 1974.

Kalil, R. E., \& Freedman, S. J. Compensation for auditory rearrangement in absence of observer movement. Perceptual and Motor Skills, 1967, 24, 475-478.

Kelso, J. A. S., Cook, E., Olson, M. E., \& Epstein, W. Allocation of attention and the locus of adaptation to displaced vision. Journal of Experimental Psychology: Human Perception and Performance, 1975, 1, 237-245.
Matin, L. Eye movements and perceived visual direction. In D. Jameson \& L. M. Hurvich (Eds.), Handbook of sensory physiology (Vol. VII/4), Visual Psychophysics. Berlin: Springer, 1972.

Pick, H. L., JR. W WRren, D. H., \& HAY, J. C. Sensory conflict in judgments of spatial direction. Perception \& Psychophysics, $1969,6,203.205$.

Platt, B. B., \& Warren, D. H. Auditory localization: The importance of eye movements and a textured visual environment. Perception \& Psychophysics, 1972, 12, 245-248.

Radeau, M. Adaptation au déplacement de l'espace visuel: Contribution expérimentale. Unpublished dissertation, Université libre de Bruxelles, 1973. (a)

RADEAU, M. The locus of adaptation to auditory-visual conflict. Perception, 1973, 2, 327-332. (b)

RADEAU, M. Adaptation au déplacement prismatique sur la base d'une discordance entre la vision et l'audition. Année Psychologique, 1974, 74, 23-34.

Radeau, M., \& Bertelson, P. Adaptation à un déplacement prismatique sur la base de stimulations exafférentes en conflit. Psychologica Belgica, 1969, 9, 133-140.

RAdEAU, M., \& Bertelson, P. The aftereffects of ventriloquism. Quarterly Joumal of Experimental Psychology, 1974, 26, 63-71.

Rock, I., \& Harris, C. S. Vision and touch. Scientific American, $1967,216,96-104$.

Stratton, G. M. Vision without inversion of the retinal image. Psychological Review, 1897, 4, 341-360, 363-481.

Tномаs, G. J. Experimental study of the influence of vision on sound localization. Journal of Experimental Psychology, 1941, 28. 167-177.

ThurLow, W. R. G., \& JACK, C. E. Certain determinants of the "ventriloquism effect." Perceptual and Motor Skills, 1973, 36, 1171-1184.

W ALKER. J. Natural visual capture in bilateral length comparisons. Perception \& Psychophysics, 1972, 11, 247-251.

W ARREN, D. H. Intermodality interaction in spatial localization. Cognitive Psychology, 1970, 1, 114-133.

WeERTs, T. C., \& ThurLow, W. R. The effect of eye position and expectation on sound localization. Perception \& Psychophysics, 1971, 9. 35-39.

WELCH, R. B. Research on adaptation to rearranged vision: 1966-1974. Perception, 1974, 3, 367-392.

Willey, C. F., Inglis, E., \& Pearce, C. H. Reversal of auditory localization. Journal of Experimental Psychology, 1937, 20, 114-130.

Witkin, H. A., WAPNeR, S., \& Leventhal, T. Sound localization with conflicting visual and auditory cues. Journal of Experimental Psychology, 1952, 43, 58-67.

Young, P. T. Auditory localization with acoustical transposition of the ears. Joumal of the Experimental Psychology, 1928, 11. 399-429.

(Received for publication February 4, 1976; revision accepted June $23,1976$. ) 